\title{
HERBERT SCREW FIXATION OF SCAPHOID FRACTURES
}

\author{
S. L. FILAN, T. J. HERBERT \\ From St Luke's Hospital, Sydney, Australia
}

W

Te reviewed the records of 431 patients who had open reduction and internal fixation of the scaphoid performed by one surgeon (TJH) over a 13-year period. The Herbert bone screw provided adequate internal fixation without the use of plaster immobilisation, promoting a rapid functional recovery.

On average, patients returned to work 4.7 weeks after surgery and wrist function was significantly improved, even when the fracture failed to unite. Healing rates for acute fractures were better than those reported for plaster immobilisation and were independent of fracture location. In the case of established nonunions, healing depended on the stage and location of the fracture, but the progress of arthritis was halted and carpal collapse significantly improved.

Internal fixation of the scaphoid using the Herbert bone screw, although technically demanding, has few complications and appears to offer significant advantages over other methods of treatment.

J Bone Joint Surg [Br] 1996;78-B:519-29.

Received 13 December 1995; Accepted after revision 7 March 1996

The Herbert screw has become widely accepted as a mode of treatment (Bunker, McNamee and Scott 1987; Ford et al 1987; DeMaagd and Engber 1989; Smith, Helm and Tonkin 1991; Dent, Mitchell and Sharma 1992; dos Reis et al 1993; Martini and Schiltenwolf 1993). Herbert and Fisher first described the technique in 1984, and proposed a classification of scaphoid fractures and a grading system for reporting results. Their prospective series of 158 acute fractures and nonunions showed that Herbert screw fixation gave enough stability to allow healing of the scaphoid without additional plaster immobilisation. Despite this, most other reports of the Herbert screw technique advocate the use of plaster splintage after operation (Moran and

S. L. Filan, BA, MA, Research Assistant

T. J. Herbert, FRCS, FRACS, Orthopaedic Surgeon and Director

Hand Unit, St Luke's Hospital Complex, 18 Roslyn Street, Potts Point, PO Box 35, New South Wales 2011, Australia.

Correspondence should be sent to $\mathrm{Mr}$ T. J. Herbert.

(C)1996 British Editorial Society of Bone and Joint Surgery 0301-620X/96/41245\$2.00
Curtin 1988; Barton 1992; Nakamura et al 1993; Mintzer, Waters and Simmons 1995), while some have questioned the fixation provided by the double-threaded screw on experimental grounds (Shaw 1987; Rankin et al 1991).

Internal fixation has yet to be accepted as a viable alternative to treatment in plaster for acute undisplaced fractures of the scaphoid (Eddeland et al 1975; Cooney, Dobyns and Linscheid 1980a; Leslie and Dickson 1981; Langhoff and Andersen 1988; Gellman et al 1989; Barton 1992; Calandra, Goldner and Hardaker 1992). For nonunion, some reports find no significant advantage over standard methods of bone grafting (Stark, Broström and Svartengren 1987, 1989; Gelberman, Wolock and Siegel 1989; Hooning van Duyvenbode et al 1991; Calandra et al 1992). The standard volar approach has been criticised as likely to produce scaphoid instability (Garcia-Elias et al 1988), and there has been some concern that the application of a jig to the scaphoid could damage the scaphotrapezial joint and lead to secondary arthritis (Barton 1992).

Thus, there are a number of unresolved questions about the indications and outcome of this technique. Does it provide adequate fixation for early postoperative use of the wrist without external splintage? Does rigid internal fixation accelerate fracture healing and recovery of wrist function and improve the prognosis for scaphoid fractures? Which scaphoid fractures and nonunions should be treated surgically? Are there significant complications?

To address these questions, we have reviewed 431 cases in which screw fixation of the scaphoid was performed by the originator (TJH). We believe that this experience has provided sufficient data to answer these questions and to give useful information about the behaviour of scaphoid fractures.

\section{PATIENTS}

The operations were carried out over 13 years from September 1981, after the end of the series reported by Herbert and Fisher (1984), to December 1994. There were 82 acute fractures and 349 cases of nonunion (Table I). We have excluded 40 patients with inadequate clinical records, five with complex injuries such as a type-B4 fracture dislocation, and 12 with congenital or healing disorders such as Down's syndrome and diabetes. We included 48 revision operations in patients with symptoms after failed previous surgery.

Of the 431 patients, $90 \%$ were male and the dominant hand was involved in $51 \%$. Their average age was 26 years 
Table I. Details of fracture according to type

\begin{tabular}{|c|c|c|c|c|c|c|c|}
\hline \multirow{2}{*}{$\begin{array}{l}\text { Fracture } \\
\text { type }\end{array}$} & \multirow[b]{2}{*}{ Number } & \multirow{2}{*}{$\begin{array}{l}\text { Mean } \\
\text { delay } \\
\text { (range) }\end{array}$} & \multicolumn{2}{|c|}{ Previous treatment } & \multicolumn{2}{|c|}{ Approach } & \multirow{2}{*}{$\begin{array}{l}\text { Bone } \\
\text { graft }\end{array}$} \\
\hline & & & POP & Surgery & Volar & Dorsal & \\
\hline$\overline{\mathrm{B} 1}$ & 16 & $2.3 \mathrm{wk}$ & 6 & - & 16 & - & 4 \\
\hline B2 & 49 & $2.8 \mathrm{wk}$ & 28 & - & 49 & - & 14 \\
\hline B3 & 17 & $2.7 \mathrm{wk}$ & 5 & - & 10 & 7 & 3 \\
\hline D1 & 131 & $\begin{array}{l}8.5 \mathrm{mth} \\
(7 \mathrm{wk} \text { to } 7 \mathrm{yr})\end{array}$ & 103 & 9 & 100 & 31 & 81 \\
\hline D2 & 161 & $\begin{array}{l}25.3 \mathrm{mth} \\
\text { ( } 7 \mathrm{wk} \text { to } 20 \mathrm{yr} \text { ) }\end{array}$ & 96 & 22 & 122 & 39 & 157 \\
\hline D3 & 57 & $\begin{array}{l}52.4 \mathrm{mth} \\
\text { (3 mth to } 25 \mathrm{yr} \text { ) }\end{array}$ & 29 & 17 & 35 & 22 & 54 \\
\hline
\end{tabular}

(14 to 68; sD 9.2). Their occupations in terms of wrist loading were heavy manual in 157 , light manual in 125 and clerical in 147. The cause of fracture had been sport in $45 \%$, mostly at football, and motor-cycle accidents in $20 \%$. About $30 \%$ of the injuries were subject to compensation claims. Of the patients with nonunion, $54 \%$ had originally been treated in plaster for an average of 8.9 weeks ( 1 to 66 ; SD 8.0).

A standard Herbert bone screw was used in 409 and a mini Herbert screw in 22. Thirty fractures required supplementary Kirschner wires.

\section{METHODS}

Assessment. All 431 patients had a preoperative assessment which was noted on a standard form. This recorded the mechanism of injury, previous treatment, symptoms, and disability for work and for sport. Clinical examination included the assessment of swelling, tenderness, passive range of movement in both wrists, and grip strengths measured by a Jamar dynamometer with the elbow at $90^{\circ}$ and neutral forearm rotation. Any joint crepitus or instability was noted. Standard four-view radiographs of both wrists were taken preoperatively, the same technique also being used at follow-up examinations (Fig. 1). Posteroanterior (PA) views of the wrist, in full ulnar and radial deviation, were used to compare the shape and mobility of the scaphoid with those of the normal uninjured side. True lateral views in neutral flexion gave the best indication of any carpal collapse and $45^{\circ}$ oblique views showed the distal and proximal poles of the scaphoid best. Tomography, CT and MRI were not used routinely. All the fractures were classified according to Herbert and Fisher (1984), modified as shown in Figure 2.

Indications. Screw fixation was used for acute fractures which were unstable (type B) or if the patient requested internal fixation. Reconstruction of nonunion (type D) was advised for symptomatic cases and in asymptomatic wrists in patients under 45 years of age. Surgery was not performed for patients with advanced radiocarpal osteoarthritis, when there was a fragmented proximal pole, in skeletally immature patients or in asymptomatic patients over the age of 45 years.

Operative technique. The technique described by the senior author was used in all cases (Herbert and Fisher 1984; Herbert 1990, 1994; Herbert and Carter 1993). A volar approach was used for fractures in the distal two-thirds of the bone, and a direct dorsal approach for those in the proximal third. Operative details were recorded in a standard format which included the state of the synovium and articular cartilage and the presence of any adhesions or soft-tissue interposition at the fracture site. The degrees of mobility and deformity were carefully assessed, as was the condition of the fracture surfaces. The vascularity of both

Table II. Scoring system for data collection

\begin{tabular}{|c|c|c|c|c|}
\hline \multirow[b]{2}{*}{ Feature } & \multicolumn{4}{|l|}{ Grade } \\
\hline & $\mathbf{0}$ & 1 & 2 & 3 \\
\hline Arthritis & None & $\begin{array}{l}\text { Mild } \\
\text { (subtle pointing of } \\
\text { styloid/scaphoid) }\end{array}$ & $\begin{array}{l}\text { Moderate } \\
\text { (clear changes, } \\
\text { slight joint } \\
\text { narrowing) }\end{array}$ & $\begin{array}{l}\text { Severe } \\
\text { (large osteophytes, } \\
\text { narrow joint space) }\end{array}$ \\
\hline $\begin{array}{l}\text { DISI* deformity } \\
\text { (degrees) } \dagger\end{array}$ & $<10$ & 10 to 14 & 15 to 19 & $>20$ \\
\hline $\begin{array}{l}\text { Radiological } \\
\text { ischaemia }\end{array}$ & None & Sclerotic & $\begin{array}{l}\text { Loss of } \\
\text { trabecular } \\
\text { structure }\end{array}$ & Fragmentation \\
\hline $\begin{array}{l}\text { Vascularity } \\
\text { at operation }\end{array}$ & Normal & Patchy sclerosis & $\begin{array}{l}\text { Complete } \\
\text { sclerosis }\end{array}$ & $\begin{array}{l}\text { Fragmented, } \\
\text { soft bone }\end{array}$ \\
\hline
\end{tabular}




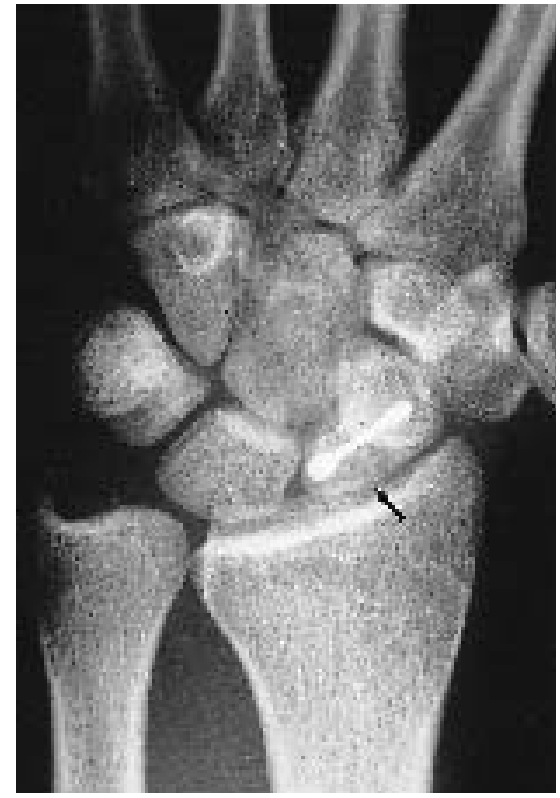

Fig. 1a

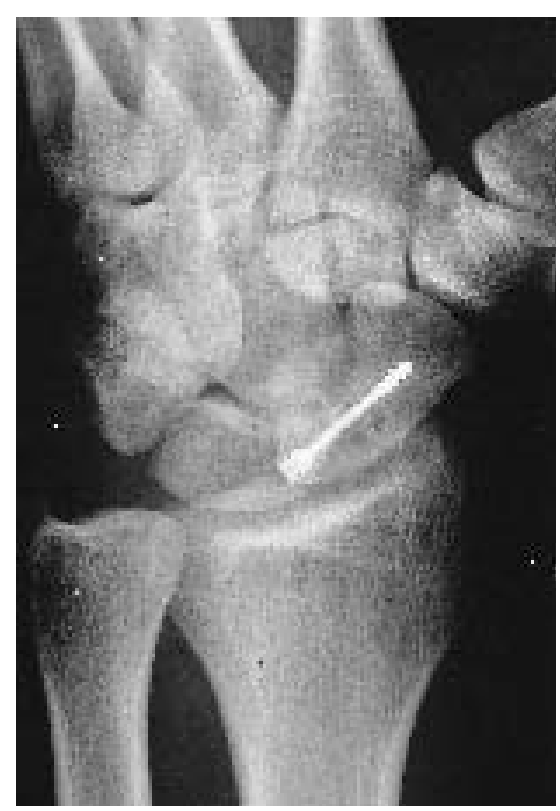

Fig. 1c

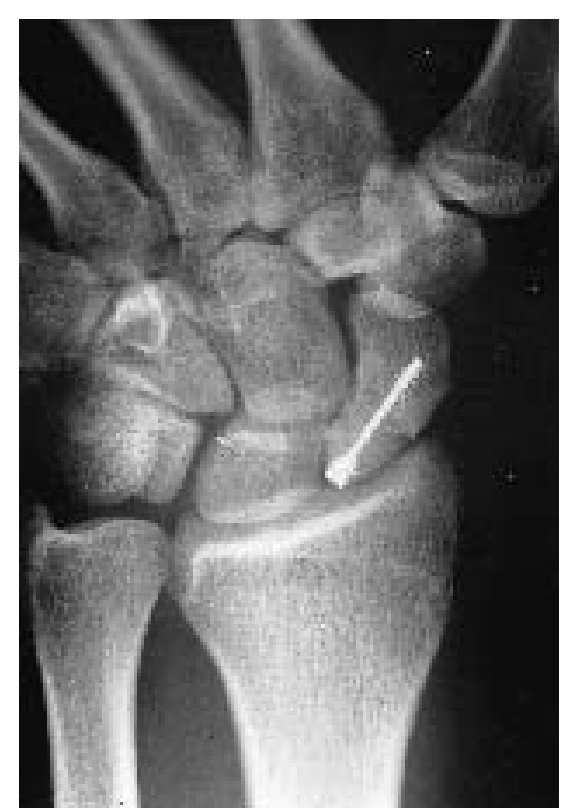

Fig. 1b

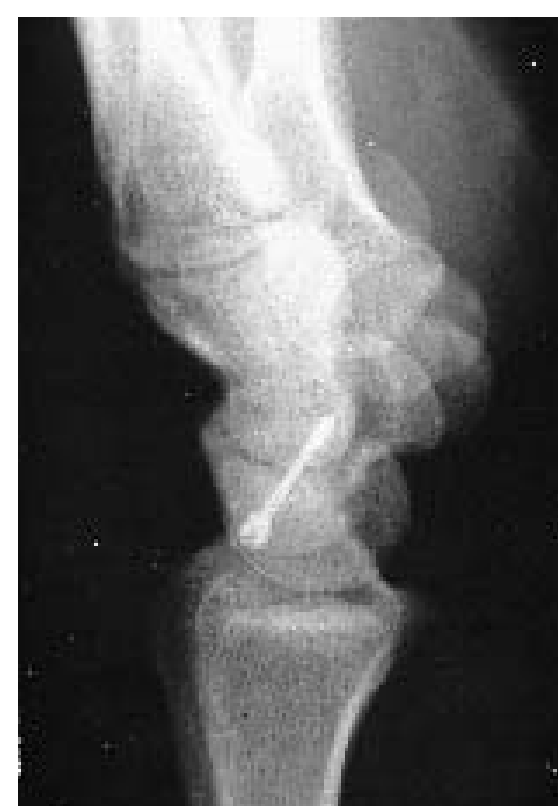

Fig. 1d
The standard four-view radiographs: PA radial (a) and ulnar (b) deviation, $45^{\circ}$ oblique (c) and true lateral (d). The lucency seen in the radial deviation film (arrow) indicates nonunion by the criteria used in our study. bone fragments was graded (Table II), recording the degree of sclerosis and observed bleeding.

All the articular surfaces of the scaphoid were either seen or carefully palpated to assess deformity; this was corrected as accurately as possible using an appropriate technique of bone grafting. The reduction jig was used when possible, both to compress the fracture with or without an interposed bone graft, and to facilitate insertion of the screw.

Acute fractures (type B) were grafted when there was comminution or a tendency to collapse under compression. For fibrous union (type D1), synovial adhesions and interposed fibrous tissue were carefully removed without destabilising the fracture, and cancellous graft was used to fill any defects after curetting out all fibrous tissue and cysts. All pseudarthroses (types D2 and D3) had excision of both fracture surfaces with an osteotome and were then reconstructed using a carefully fashioned corticocancellous bone block. This was obtained from the iliac crest and used to restore length and stability (Fig. 3).

For small fractures of the proximal pole using a dorsal approach, no attempt was made to lengthen the scaphoid. These fractures appear to be avulsion injuries and are rarely completely unstable. To avoid disrupting the residual stability and vascularity of the proximal fragment, the fracture was manipulated as little as possible; curettage and cancellous grafting were performed after gently prising open 


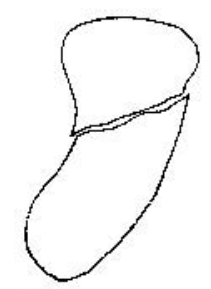

B1

Distal Oblique

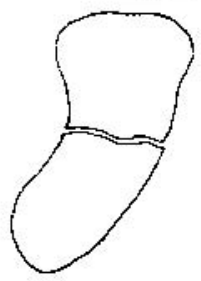

$\mathrm{B2}$
Acute Fractures ( $\leq 6$ weeks old)

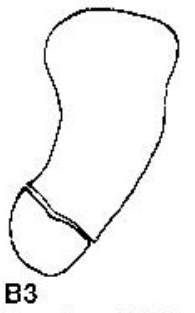

Proximal Pole

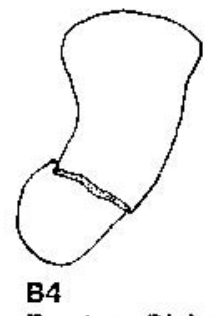

Fracture Dislocation
Fig. 2

Modified staging system for scaphoid fractures. Type-A fractures are not illustrated. Types B5 (comminuted) and C (delayed union) have been omitted from the classification because they did not form natural groups. Smith et al (1991) noted the questionable validity of type $\mathrm{C}$.

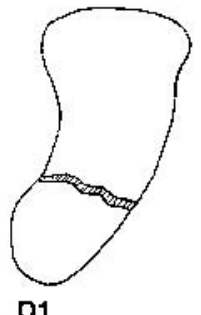

Fibrous Union

No deformity

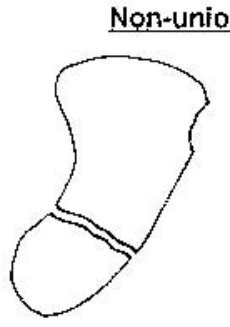

D2

Pseudarthrosis

Early deformity

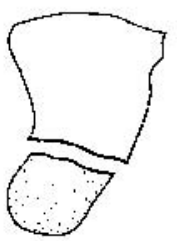

D3

Sclerotic Pseudarthrosis Advanced deformity

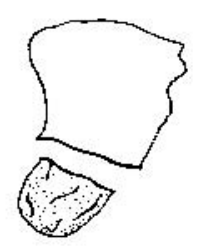

D4

Avascular Necrosls

Fragmented proximal pole

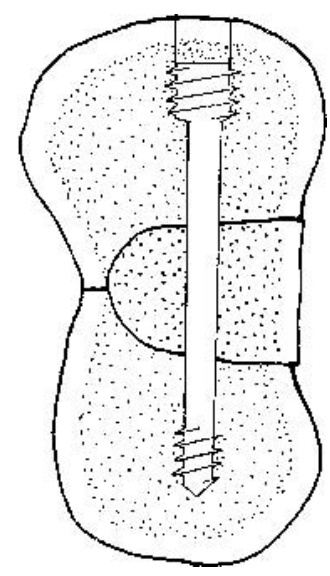

Fig. 3a

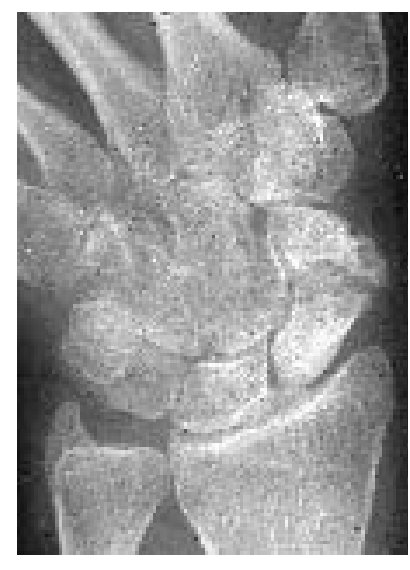

Fig. $3 b$

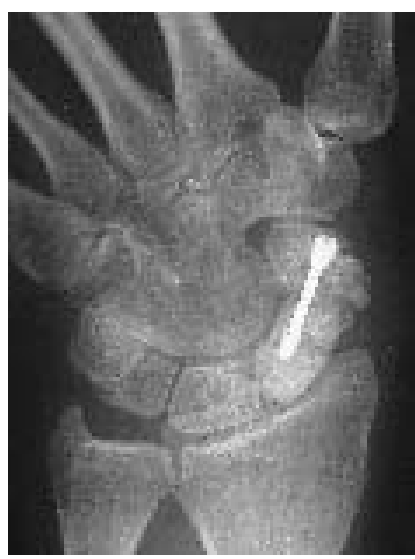

Fig. 3c

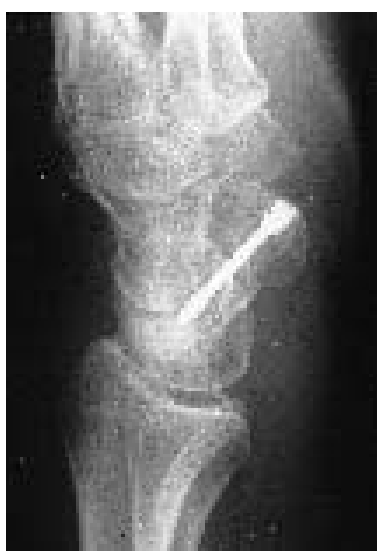

Fig. 3d

A corticocancellous graft (a) gives stability to compression after the complete excision of a scaphoid pseudarthrosis. The preoperative collapse and shortening (b) have been corrected by a successful reconstruction (c). In the lateral view (d) the cortical element of the graft is visible.

the dorsal part of the fracture. The articular surfaces were carefully reduced and held by a temporary Kirschner wire. The Herbert screw was then inserted freehand, using the drill guide applied to the apex of the proximal pole with the wrist in full flexion, and aimed along the midline axis of the scaphoid. We now use the mini Herbert bone screw to fix small fractures of the proximal pole; its smaller diameter increases the area of bone contact and the increased pitch differential enhances fixation when using the freehand method. Intraoperative image-intensifier screening was used to confirm satisfactory positioning of the screw.

Most bone grafts were taken from the contralateral iliac crest, but in the last two years, we have used some vascularised radial grafts (Zaidemberg, Siebert and Angrigiani 1991) to supplement the reconstruction of selected cases in which there is severely impaired vascularity. Even when the proximal scaphoid appeared to be ischaemic at surgery, reconstruction was performed, provided that the bone fragments were suitable for internal fixation. Only when the proximal pole was soft or fragmented (type D4) was reconstruction abandoned in favour of a salvage procedure.

Postoperative management. A firm padded bandage was used to support the wrist for the first two weeks and then, after the removal of sutures, the patient started active 
mobilising exercises of the wrist. During the first six to eight weeks after surgery, patients were advised to avoid full loading of the wrist and to refrain from contact sports. Light removable splints were prescribed only when the patient was unlikely or unwilling to comply with this advice and printed sheets were provided to explain the postoperative regime. All restrictions were lifted after three months whether or not the fracture had healed.

Review. Patients were asked to attend for routine review at two and six weeks, three months and one year, additional visits being scheduled as required. Standard radiographs were taken at each visit and a full clinical assessment was recorded.

Patients with delayed union or nonunion after operation were asked to attend for regular review every 6 to 12 months, even if they were free from symptoms. Revision operations were performed only for persisting symptoms or disability associated with nonunion, osteoarthritis or avascular necrosis. Reoperation was not advised for asymptomatic nonunion with stable fixation.

Patients who failed to attend for the six-month review were sent a questionnaire and encouraged to return for late clinical and radiological assessment. For 52 patients only these questionnaires were available; the assessment of union was then based on the last available radiograph at a minimum of three months after operation.

All records and radiographs were reviewed by one author (SLF), who graded the clinical results as described by Herbert and Fisher (1984). Radiological results were more rigorously defined: fractures were recorded as united only if cross-trabeculation was present and the fracture line was no longer visible on any of the four standard views (see Figure 1 for an example of strictly defined nonunion). Any lucency around the screw threads was taken to indicate nonunion, avascular necrosis or both, even when the fracture itself appeared to have healed (Filan and Herbert 1995). For patients with incomplete radiological records, the outcome as regards union was considered to be unknown and such cases were excluded from the calculation of rates of union.

Table II shows the scoring system used for clinical, radiological and operative findings. We performed statistical analysis using the paired $t$-test for numerical data (range of motion, grip) and chi-squared analysis for qualitative scoring.

\section{RESULTS}

Operative findings. Most acute type-B fractures were completely unstable, often with extensive haemarthrosis and marked comminution. About one-third of these had soft-tissue interposition at the fracture site. These findings correlated poorly with the preoperative radiographs, which seldom showed any obvious displacement or deformity (Fig. 4).

By contrast, type-D1 fractures showed the least synovial reaction, instability and deformity, and at first sight often appeared to have healed. Despite this, $79 \%$ of the 131 were found to have synovial adhesions which frequently communicated with fibrous cysts within the fracture site. Most of the pseudarthroses (types D2 and D3) were unstable and had considerable collapse. Synovial adhesions at the fracture site were common and were usually associated with an effusion.

Vascularity, as observed at operation, did not correlate with the preoperative radiological assessment. In general, it was found to depend on the site of fracture, the previous treatment and the time from injury.

Follow-up. Of the 431 patients, only 304 (70.5\%) had adequate follow-up for a minimum of six months to allow assessment of the final outcome. The mean follow-up for these 304 patients was 34.2 months and all subsequently reported results relate only to this subgroup.

Function. Wrist function (Fig. 5), as assessed by range of

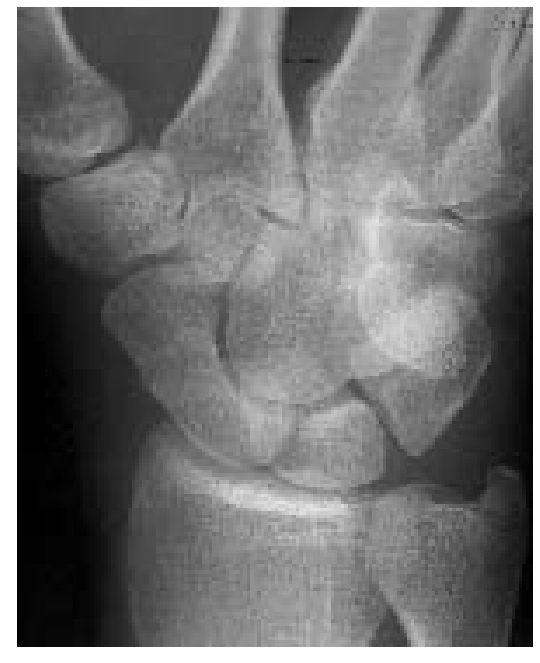

Fig. 4a

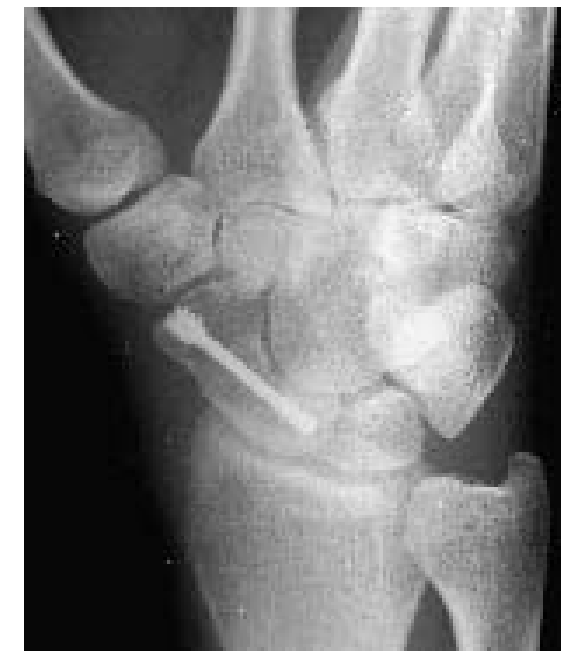

Fig. 4b
A 35-year-old woman fractured her left scaphoid playing tennis (a). After five days in plaster, she requested internal fixation, and at operation nine days after injury an unstable oblique fracture was found to have synovial adhesions with ligamentous interposition between the fragments. Five weeks later, the fracture had united (b) and she resumed full sporting activities. 


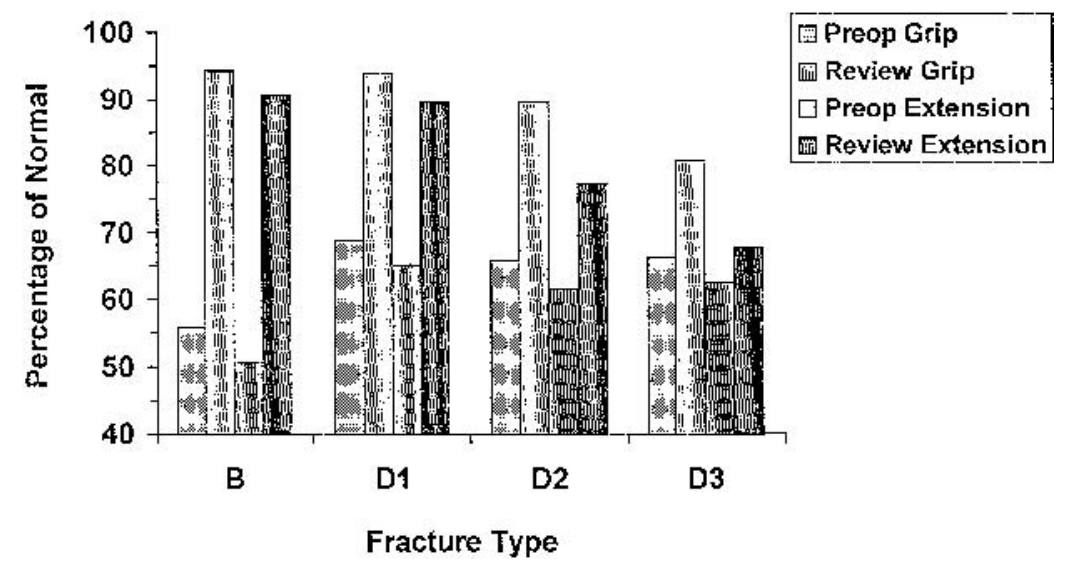

Fig. 5

Grip and wrist extension before and after scaphoid reconstruction, as percentages of the normal side.

movement and grip strength, was dramatically improved after reconstruction of the scaphoid. The exception to this was a lack of improvement of wrist extension after reconstruction of type-D3 fractures. Internal fixation of the scaphoid also produced a dramatic decrease in pain. Most patients had moderate or severe pain preoperatively, but $86 \%$ had no pain at the latest review. Postoperative pain was nearly always associated with avascular necrosis or osteoarthritis, but successful reconstruction did appear to relieve some of the symptoms of radioscaphoid impingement or arthritis. Of 68 patients with radiological evidence of radiocarpal osteoarthritis preoperatively, only 12 required radial styloidectomy for persistent pain due to radioscaphoid impingement.

Of the 304 patients, 277 (91\%) were able to return to their preinjury work at a mean of 4.7 weeks after surgery. At the latest review 27 were not working, of whom 15 were receiving workers' compensation.

Radiological results. The rates of union shown in Tables III and IV demonstrate that, overall, union depends on the type of fracture and its location within the scaphoid. For acute fractures the rate was $88 \%$ and did not vary significantly with the location of the fracture.

Fibrous nonunion (type D1) affecting the distal twothirds of the scaphoid gave similar results to those of acute fractures, but the rate of union was reduced to $75 \%$ for fractures of the proximal pole (Table IV). Nonunion of types D2 and D3 gave progressively worse results: only one in three fractures of the proximal pole with ischaemic bone achieved complete radiological union (Table IV). The functional results (Fig. 5) were very different from the radiological results.

We found dorsal intercalated scaphoid instability (DISI) in only 9 of the 56 acute fractures; this was not improved after surgery. As expected, however, the amount of carpal collapse increased progressively with delay from the initial fracture: $45 \%$ of the patients with pseudarthroses (types D2 and D3) had this deformity, which was significantly improved by surgery (Table V).

Our results appear to show that successful scaphoid reconstruction can slow down the onset of degenerative changes. The preoperative incidence of radiocarpal arthritis had not significantly increased at the time of latest review (Table V), and this applies even when the fracture had not united radiologically.

Six patients had significant malunion of the scaphoid, but none of these had any complaints.

Table IV. Comparison of rate of union for type-D fractures related to their location in patients with at least 6 months' follow-up

\begin{tabular}{|c|c|c|c|c|}
\hline \multirow{2}{*}{$\begin{array}{l}\text { Fracture } \\
\text { type }\end{array}$} & \multicolumn{2}{|l|}{ Body } & \multicolumn{2}{|c|}{ Proximal pole } \\
\hline & Number & \% Union & Number & \% Union \\
\hline $\bar{D} 1$ & 58 & 91 & 16 & 75 \\
\hline D2 & 76 & 76 & 34 & 44 \\
\hline D3 & 31 & 58 & 19 & 37 \\
\hline
\end{tabular}

Table V. DISI deformity and radiocarpal arthritis (percentage) in scaphoid pseudarthrosis (types D2 and D3)

\begin{tabular}{lccccc}
\hline & None & Mild & Moderate & Severe & p value \\
\hline DISI deformity & & & & & \\
$\quad$ Preop & 55 & 18 & 10 & 17 & 0.032 \\
$\quad$ Review & 70 & 14 & 8 & 8 & \\
Radiocarpal & & & & & \\
osteoarthritis & & & & & \\
$\quad$ Preop & 60 & 23 & 14 & 3 & 0.224 \\
$\quad$ Review & 51 & 28 & 14 & 7 & \\
\hline
\end{tabular}

Table III. Rate of union related to type of fracture for patients with at least 6 months' follow-up

\begin{tabular}{lcccl}
\hline Fracture type & & Union & Nonunion & \% Union \\
\hline Distal oblique & B1 & 9 & 1 & 90 \\
Waist & B2 & 29 & 4 & 88 \\
Proximal pole & B3 & 11 & 2 & 85 \\
Fibrous union & D1 & 65 & 9 & 88 \\
Pseudarthrosis & D2 & 73 & 37 & 66 \\
$\begin{array}{l}\text { Sclerotic } \\
\text { pseudarthrosis }\end{array}$ & D3 & 25 & 25 & 50
\end{tabular}


Complications. The most common complication of surgery was a tender, hypertrophic scar, seen in 13\%. Twenty patients complained of postoperative pain and swelling at the donor site of the bone graft, although this resolved with time. Four superficial and one deep wound infection resolved satisfactorily with conservative treatment; in none was the outcome affected adversely.

In 14 wrists, there was some protrusion of the screw; one was revised successfully at three weeks, and one developed nonunion. Seven had the protruding screw removed after fracture healing; the other five remained asymptomatic and did not require further surgery.

Four patients had early signs of reflex sympathetic dystrophy (RSD) after surgery. In two these resolved spontaneously, but two patients developed carpal tunnel syndrome which required surgical decompression.

Only two wrists showed instability of the scaphoid after surgery. One had sustained a tear of the scapholunate ligament at the time of injury; the other appeared to have a late rupture of this ligament.

Revision surgery. Avascular necrosis developed after surgery in 20 scaphoids, all of which required further operations. In one case a very small necrotic fragment of the proximal pole was excised and the scaphoid stabilised by dorsal capsulorrhaphy. Five wrists had a midcarpal fusion. In 14 cases, the necrotic proximal pole was excised and replaced, using a stabilised silicone implant in 13 and an osteochondral autograft in one.

\section{DISCUSSION}

One of the most disappointing aspects of this review was our difficulty in achieving adequate follow-up. Many of our patients come from rural areas and are unwilling to attend

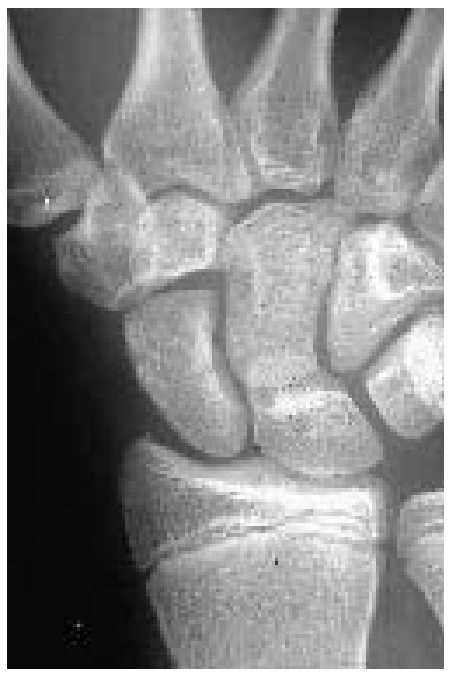

Fig. 6a

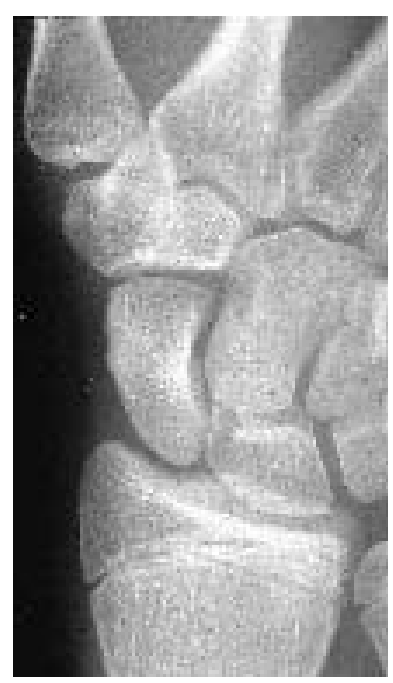

Fig. 6b

for routine review when they have no complaints. Some from remote areas were never reviewed by us after their discharge from hospital, preferring to be followed up by their local doctor who contacted us only if there were problems. In several cases, late review was achieved only when the patient attended some years later for the treatment of a new and unrelated injury.

We believe that this difficulty leads to an adverse bias: patients with problems are more likely to return for review; those with no symptoms are lost to follow-up. Of the patients responding to our questionnaire, only one reported residual symptoms. This patient was recalled and was found to have persistent nonunion. No others had symptoms which they considered severe enough to warrant further investigation or treatment. This experience is in direct opposition to that reported by Wildner (1995) after shoulder surgery. The young, active men who most commonly present with scaphoid fractures are very different from patients having shoulder or hip surgery and loss to review may be for different reasons.

Operative findings. We found poor correlation between preoperative radiographs and the findings at operation; this underlines the inherent weakness of managing scaphoid fractures on the basis of their radiological appearance. For scaphoid nonunion, we agree with Green (1985) that radiographs are an unreliable indicator of scaphoid vascularity; this is best assessed at operation. Acute fractures were nearly always worse than suggested by the radiograph (Fig. 4): we found soft tissue interposed at the fracture site in 28 acute cases. Some acute fractures which were invisible on initial radiographs showed a large gap only a few weeks later, and this suggests that interposed synovium may play a role in the development of nonunion. Osterman and Mikulics (1988) recognise that synovium may produce

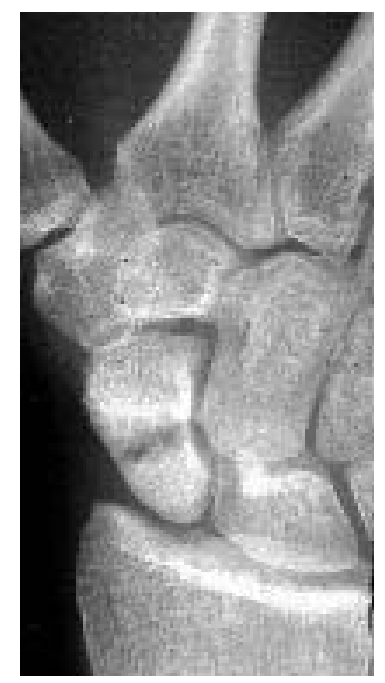

Fig. 6c

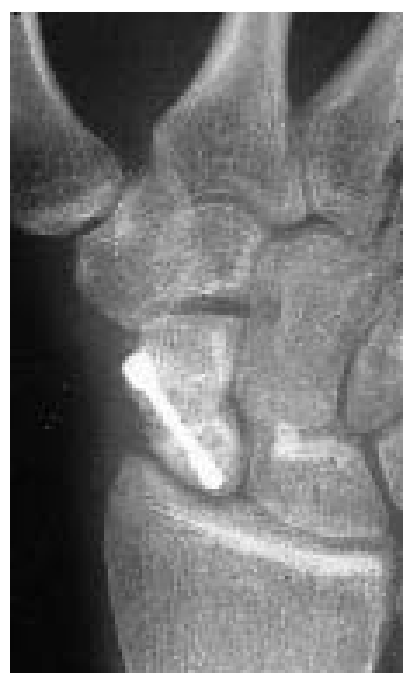

Fig. 6d

A 15-year-old boy with an acute scaphoid fracture (a) treated by plaster immobilisation. Two months later the fracture appeared to have united (b). The patient failed to attend for follow-up, but returned six years later complaining of slowly deteriorating wrist function. Radiographs showed the classical signs of late failure after fibrous nonunion (c). After reconstruction and Herbert screw fixation, the nonunion healed (d) and the patient has returned to work as a motor mechanic. 
cystic change and this was confirmed in our series; we found that sites of nonunion had a high incidence of synovial adhesions, often in communication with fibrous cysts. This may explain the late nonunion which may follow the apparent healing of acute fractures which have been treated conservatively (Fig. 6). We believe that the role of synovial fluid and synovial adhesions in producing nonunion of the scaphoid is not fully appreciated, which may account for a certain complacency about treating scaphoid fractures in plaster.

Stability of internal fixation. Our study has shown that internal fixation using the Herbert bone screw results in rapid symptomatic relief and functional recovery, even when the scaphoid fails to heal. Review of these cases shows that the screw provides sufficient stability to allow normal use of the wrist. In a few patients, we have seen union occur as late as two to three years after surgery (Fig. 7 ); this suggests that fixation remains secure enough to allow slow revascularisation of the bone. We should emphasise that none of these patients was using an external splint. By contrast, we encourage normal use of the wrist. This leads to rapid functional improvement and helps to prevent the development of joint stiffness and osteoporosis (Salter 1982; Skirven and Trope 1994).

Apart from the one case of screw protrusion which we report, we do not attribute any late nonunions to failure of fixation. Several of our patients sustained further injuries to their wrist within three months of surgery, but in none of these was outcome affected adversely. We therefore question the relevance of recent work which has compared the mechanical properties of different fixation devices in cadaver or foam model scaphoids (Shaw 1987, 1991; Carter et al 1991; Rankin et al 1991; Newport, Williams and Bradley 1996). Our review has shown that a correctly inserted Herbert screw provides adequate fixation to allow early movement. While the same may be true for other devices, we believe that the challenge for the future is to secure adequate fixation with the least possible trauma to the bone and the surrounding joints and soft tissues.

Apart from patients who developed avascular necrosis, the only failures of fixation which we have seen after surgery were in patients referred from elsewhere when the wrist had been immobilised in plaster postoperatively. All these patients showed progressive osteoporosis after operation; we believe that this weakening of the bone led to failure of fixation. We therefore advocate early postoperative mobilisation and condemn the use of plaster after successful internal fixation.

Fracture healing. It is uncertain whether internal fixation accelerates healing, but it seems that in acute scaphoid fractures it not only prevents the complications associated with cast treatment, but also improves the prognosis (see Fig. 4). Many authors still believe that the rate of union for conservative treatment of undisplaced fractures is about 95\% (Osterman and Mikulics 1988; Gelberman et al 1989; Calandra et al 1992), but firm evidence for such optimism is lacking. Many papers do not have a clear definition of union and often base it on radiological appearance when the wrist comes out of plaster, or shortly after (Stewart 1954; London 1961; Eddeland et al 1975; Cooney et al 1980a; Leslie and Dickson 1981; Morgan and Walters 1984; Langhoff and Andersen 1988; Gellman et al 1989). Others have included cases in which the fracture line remains visible (Goldman, Lipscomb and Taylor 1969).

The difficulty of diagnosing union from early radiographs has been highlighted by Dias et al (1988) who showed that films taken 12 weeks after injury were unreliable; they recommended radiological follow-up for at least six months. In a subsequent paper Dias, Brenkel and Finlay (1989) reviewed 82 conservatively-treated fractures of the scaphoid waist after approximately two years: ten had definite nonunion and another 20 still had a visible fracture

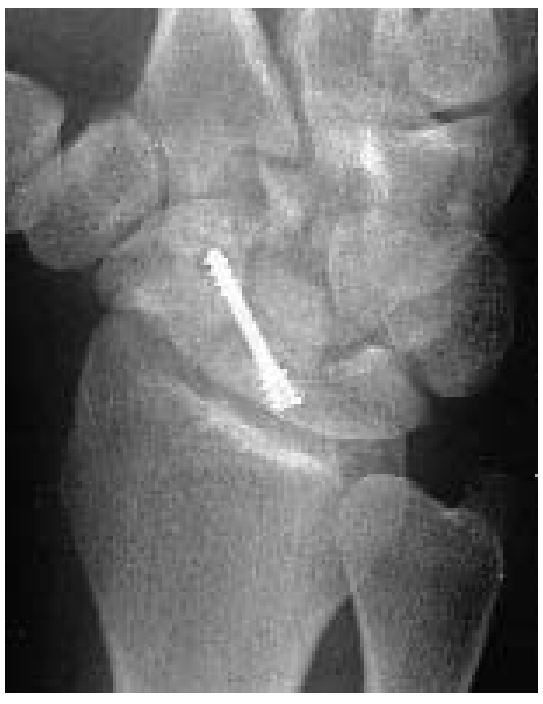

Fig. 7a

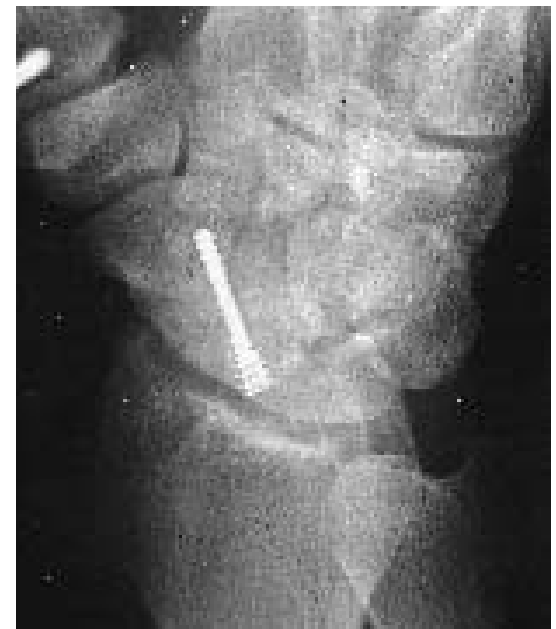

Fig. $7 \mathrm{~b}$
A 21-year-old football player fractured his right scaphoid but the diagnosis was delayed and a D2 proximal pole nonunion was reconstructed after eight months. Sixteen months after surgery the fracture line was still visible (a). At 33 months, after he had sustained a Bennett's fracture which was also fixed, the fracture had finally united (b). 
line. By our criteria, these would all be classified as nonunion, giving a true union rate of $63 \%$ for simple fractures of the waist. The rate of union which we found, $88 \%$ for all types of acute fracture, suggests that internal fixation does improve the prognosis for healing.

Our rate of union of $82 \%$ for scaphoid nonunion (type D1 and type D2 body) is similar to the average of $80 \%$ reported after conventional bone grafting (Russe 1960; Cooney, Dobyns and Linscheid 1980b; Stark et al 1987; Barton 1992). Some have reported more optimistic results (Mulder 1968), but the quality and extent of review are sometimes questionable. Fernandez (1990), in his study of lag screw fixation, admits that successful treatment "does not depend on the implant used but rather on careful case selection and precise surgical technique" (our emphasis). Only if other methods can be shown to achieve significantly better results for all types of nonunion, can we deduce that internal fixation may adversely affect healing of scaphoid nonunion.

Functional results. Our results confirm that internal fixation leads to better functional results than standard techniques of bone grafting (Warren-Smith and Barton 1988), presumably because of the accuracy of scaphoid reconstruction combined with the benefits of early postoperative movement. Even more significant is the fact that improved function appears to be maintained even in cases of persistent nonunion (Dent et al 1992). We therefore believe that internal fixation is justified, even when there is completely ischaemic nonunion (D3). The sustained functional improvement that can be achieved is preferable to the results of other treatments such as fusion or proximal row carpectomy (Barton 1992; Kirschenbaum et al 1993; Ashmead et al 1994; Krakauer, Bishop and Cooney 1994; Tomaino, Delsignore and Burton 1994).

We do not normally advise reoperation after failure of scaphoid reconstruction, which we assume to be related to impaired vascularity. As long as the scaphoid remains stable, the wrist continues to function well (Fig. 8). Reoperation under such circumstances could precipitate complete avascular necrosis and require a salvage procedure which, even at best, cannot match the functional result of a stable nonunion.

An important advantage of internal fixation is that it allows an early return to work. Few patients, especially those in manual occupations, are able to return to work wearing a cast. Morgan and Walters (1984) reported that patients with acute scaphoid fractures who had conservative treatment required an average of 8.8 weeks off work; this should be compared with the mean of 4.7 weeks in our series. The benefits are even greater after elective surgery for scaphoid nonunion. Most of these patients are young and active, and cannot easily afford to stay off work for the three to four months often required after bone grafting without internal fixation (Cooney et al 1980b).

The effect of compensation on return to work has been mentioned by Morgan and Walters (1984), who found that patients receiving compensation took longer to return to work. In our series, both compensation status and wrist loading significantly affected times of return to work (Filan 1996).

Arthritis and deformity. Stable internal fixation may not improve rates of union to a significant extent, but it has other advantages in the treatment of scaphoid nonunion. Our $2 \%$ incidence of malunion compares very favourably with the $50 \%$ reported by Jiranek et al (1992), who used standard grafting techniques. Our results also show that the progress of osteoarthritis is reduced by successful internal fixation. This may not be the case after Russe grafting (Cooney et al 1980b; Stark et al 1987; Steiger and Sennwald 1990). It seems likely that the length and shape of the
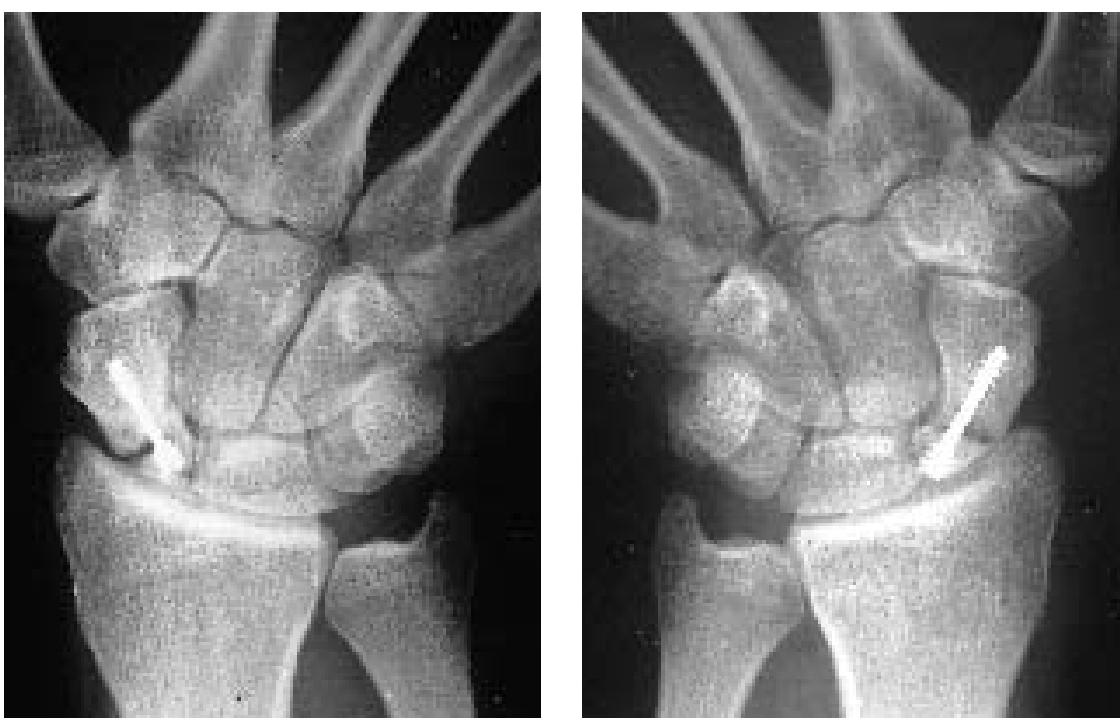

Fig. 8a
An active sportsman and shearer/wool buyer fractured his right scaphoid playing football. The fracture was not diagnosed until six months after injury and at 13 months a D3 proximal pole fracture was reconstructed, but failed to unite. He then fractured his left scaphoid and a D2 proximal pole fracture was grafted and fixed. At five years (a) and three years (b) after operation, both wrists were asymptomatic with no restriction of movement or use. 
reconstructed scaphoid are maintained more accurately by internal fixation than by immobilisation in plaster.

DISI deformity was surprisingly rare in our acute fractures, despite the inherent instability of these injuries (Gilford, Bolton and Lambrinudi 1943; Fisk 1970; Linscheid et al 1972, 1983). We found that anatomical repair of the scaphoid failed to correct this deformity, suggesting that it indicates a more complex ligament injury. By contrast, we found that carpal collapse deformity tends to progress as the scaphoid collapses, and leads to symptomatic loss of wrist extension (Nakamura et al 1991). This deformity can often be improved by surgery, although soft-tissue and capsular contractures sometimes preclude complete correction in late cases (type D3). We therefore believe that the policy of operating early for nonunion, even when it is asymptomatic, is fully justified; there is good evidence that untreated nonunion of the scaphoid leads to progressive arthritis and ischaemia (Mack et al 1984; Ruby, Stinson and Belsky 1985; Lindstrom and Nystrom 1992; Shinya and Herbert 1994).

Complications. The main disadvantage of Herbert screw fixation is its technical difficulty. The operation requires skill and practice (Bunker et al 1987; Ford et al 1987; Smith et al 1991; Martini and Schiltenwolf 1993); poor surgery leads to poor results (Adams et al 1988). With adequate experience, however, we found that the incidence of complications was low. Problems with the scar can be reduced by modifying the incision in patients at risk: we now routinely use a zig-zag incision for the volar approach. Screw protrusion should be avoided by the use of intraoperative screening (Ford et al 1987; Smith et al 1991; Nakamura et al 1993), but if the fixation is secure, minor protrusion is probably not important, since the fracture will almost certainly heal and the screw can then be removed if it causes symptoms. We have found that some scaphoids, particularly in female patients, are too small for the successful application of the jig. We revert to freehand insertion in such cases, using the mini Herbert screw, which is easier to position accurately.

We found no evidence of significant osteoarthritic changes in the scaphotrapezial joint after use of a volar approach for internal fixation. This had been a concern, but the application of the jig and insertion of the screw through the articular surface of the tubercle do not cause significant damage, as confirmed by other investigators (Martini and Schiltenwolf 1993; Callanan, Lahoti and McElwain 1995). Similarly, we have found no evidence that the volar approach causes instability of the scaphoid as suggested by Garcia-Elias et al (1988). It does transect part of the radioscaphocapitate ligament, but this does not appear to produce significant instability. We routinely repair the volar capsule with fine non-absorbable sutures, but continue to allow unrestricted movement of the wrist as soon as the skin wound has healed. The scarring associated with repair of the capsule may cause some postoperative stiffness, which may take many months to improve. We saw post- operative instability in only two cases. This was due to associated damage to the scapholunate ligament, not suspected at the time of surgery. We now inspect the scapholunate ligament routinely, even at operations through a volar approach.

\section{Conclusions}

1) There is a poor correlation between the radiological appearance of scaphoid fractures and the findings at operation. Management of scaphoid fractures should not be based solely on radiographs.

2) The Herbert bone screw can provide enough fixation to allow healing without external splintage.

3) The healing of acute fractures is better than that in conservative management and is not related to the site of the fracture. Healing of nonunion is similar to that after other techniques, but functional improvement is greater and the progress of osteoarthritis is reduced.

4) Functional recovery is much quicker after internal fixation and early mobilisation; most patients can return to work within a few weeks.

5) The technique requires some skill, but the incidence of complications is low.

\section{S. L. Filan was supported by a grant from Zimmer Inc.}

One or more of the authors have received or will receive benefits for personal or professional use from a commercial party related directly or indirectly to the subject of this article.

\section{REFERENCES}

Adams BD, Blair WF, Reagan DS, Grundberg AB. Technical factors related to Herbert screw fixation. J Hand Surg [Am] 1988;13:893-9.

Ashmead D, Watson HK, Damon C, Herber S, Paly W. Scapholunate advanced collapse wrist salvage. J Hand Surg [Am] 1994;19:741-50.

Barton NJ. Twenty questions about scaphoid fractures. J Hand Surg [Br] 1992;17:289-310.

Bunker TD, McNamee PB, Scott TD. The Herbert screw for scaphoid fractures: a multicentre study. J Bone Joint Surg [Br] 1987;69-B:6314.

Calandra JJ, Goldner RD, Hardaker WT. Scaphoid fractures: assessment and treatment. Orthopedics 1992;15:931-7.

Callanan I, Lahoti O, McElwain J. The Herbert screw in the scaphotrapezial joint: a cause for concern? Procs 6th Congress of the International Federation of Societies for Surgery of the Hand (IFSSH). 1995:O:162.

Carter FM, Zimmerman MC, DiPaola DM, Mackessy RP, Parsons JR. Biomechanical comparison of fixation devices in experimental scaphoid osteotomies. J Hand Surg [Am] 1991;16-A:907-12.

Cooney WP, Dobyns JH, Linscheid RL. Fractures of the scaphoid: a rational approach to management. Clin Orthop 1980a;149:90-7.

Cooney WP III, Dobyns JH, Linscheid RL. Nonunion of the scaphoid: analysis of the results from bone grafting. J Hand Surg [Am] 1980b; 5-A:343-54.

DeMaagd RL, Engber WD. Retrograde Herbert screw fixation for treatment of proximal pole scaphoid nonunions. J Hand Surg [Am] 1989; 14:996-1003.

Dent JA, Mitchell CA, Sharma MM. Herbert screw: results of a singlecentre trial. Injury 1992;23:228-30.

Dias JJ, Brenkel IJ, Finlay DBL. Patterns of union in fractures of the waist of the scaphoid. J Bone Joint Surg [Br] 1989;71-B:307-10.

Dias JJ, Taylor M, Thompson J, Brenkel IJ, Gregg PJ. Radiological signs of scaphoid fractures: an analysis of inter-observer agreement and reproducibility. J Bone Joint Surg [Br] 1988;70-B:299-301.

Eddeland A, Eiken O, Hellgren E, Ohlsson N-M. Fractures of the scaphoid. Scand J Plast Reconstr Surg 1975;9:234-9.

Fernandez DL. Anterior bone grafting and conventional lag screw fixation to treat scaphoid nonunions. J Hand Surg [Am] 1990;15:140-7.

Filan SL. The effect of worker's compensation on recovery from hand surgery. Med J Aust 1996;165:in press.

THE JOURNAL OF BONE AND JOINT SURGERY 
Filan SL, Herbert TJ. Avascular necrosis of the proximal scaphoid after fracture union. J Hand Surg [Br] 1995;20:551-6.

Fisk GR. Carpal instability and the fractured scaphoid. Hunterian Lecture 1968. Ann R Coll Surg Engl 1970;46:63-76.

Ford DJ, Khoury G, El-Hadidi S, Lunn PG, Burke FD. The Herbert screw for fractures of the scaphoid: a review of results and technical difficulties. J Bone Joint Surg [Br] 1987;69-B:124-7.

Garcia-Elias M, Vall A, Salo JM, Lluch AL. Carpal alignment after different surgical approaches to the scaphoid: a comparative study. J Hand Surg [Am] 1988;13:604-12.

Gelberman RH, Wolock BS, Siegel DB. Fractures and nonunions of the carpal scaphoid. J Bone Joint Surg [Am] 1989;71:1560-5.

Gellman H, Caputo RJ, Carter V, Aboulafia A, McKay M. Comparison of short and long thumb-spica casts for non-displaced fractures of the carpal scaphoid. J Bone Joint Surg [Am] 1989;71-A:354-7.

Gilford WW, Bolton RH, Lambrinudi C. Mechanism of wrist joint with special reference to fractures of scaphoid. Guy's Hosp Rep 1943; 92:52-9.

Goldman S, Lipscomb PR, Taylor WF. Immobilisation for acute carpal scaphoid fractures. Surg Gynec Obstet 1969;129:281-4.

Green DP. The effect of avascular necrosis on Russe bone grafting for scaphoid nonunion. J Hand Surg [Am] 1985;10-A:597-605.

Herbert TJ. The fractured scaphoid. St Louis. Quality Medical Publishing, 1990.

Herbert TJ. Open reduction and internal fixation using the Herbert screw. In: Gelberman RH, ed. Master techniques in orthopaedic surgery: the wrist. New York: Raven Press, 1994:87-104.

Herbert TJ, Carter P. Surgical techniques for fixation of scaphoid and other small bones. Zimmer, Inc, 1993.

Herbert TJ, Fisher WE. Management of the fractured scaphoid using a new bone screw. J Bone Joint Surg [Br] 1984;66-B:114-23.

Hooning van Duyvenbode JFF, Keijser LCM, Hauet EJ, Obermann WR, Rozing PM. Pseudarthrosis of the scaphoid treated by the MattiRusse operation: a long-term review of 77 cases. J Bone Joint Surg [Br] 1991;73-B:603-6.

Jiranek WA, Ruby LK, Millender LB, Bankoff MS, Newberg AH. Long-term results after Russe bone-grafting: the effect of malunion of the scaphoid. J Bone Joint Surg [Am] 1992;74-A:1217-28.

Kirschenbaum D, Schneider LH, Kirkpatrick WH, Adams DC, Cody RP. Scaphoid excision and capitolunate arthrodesis for radioscaphoid arthritis. J Hand Surg [Am] 1993;18:780-5.

Krakauer JD, Bishop AT, Cooney WP. Surgical treatment of scapholunate advanced collapse. J Hand Surg [Am] 1994;19:751-9.

Langhoff $\mathbf{O}$, Andersen JL. Consequences of late immobilization of scaphoid fractures. J Hand Surg [Br] 1988;13-B:77-9.

Leslie IJ, Dickson RA. The fractured carpal scaphoid: natural history and factors influencing outcome. J Bone Joint Surg [Br] 1981;63-B: 225-30.

Lindstrom G, Nystrom A. Natural history of scaphoid nonunion with special reference to 'asymptomatic' cases. J Hand Surg [Br] 1992;71: 697-700.

Linscheid RL, Dobyns JH, Beckenbaugh RD, Cooney WP III, Wood MB. Instability patterns of the wrist. J Hand Surg 1983;8:682-6.

Linscheid RL, Dobyns JH, Beabout JW, Bryan RS. Traumatic instability of the wrist: diagnosis, classification and pathomechanics. $J$ Bone Joint Surg [Am] 1972;54-A:1612-32.

London PS. The broken scaphoid bone: the case against pessimism. J Bone Joint Surg [Br] 1961;43-B:237-44.

Mack GR, Bosse MJ, Gelberman RH, Yu E. The natural history of scaphoid non-union. J Bone Joint Surg [Am] 1984;66-A:504-9.

Martini AK, Schiltenwolf M. Intermediate results in treatment of scaphoid pseudarthrosis and fracture with the Herbert screw. Aktuelle Traumatol 1993;23:317-23.
Mintzer CM, Waters PM, Simmons BP. Nonunion of the scaphoid in children treated by Herbert screw fixation and bone grafting: a report of five cases. J Bone Joint Surg [Br] 1995;77-B:98-100.

Moran R, Curtin J. Scaphoid fractures treated by Herbert screw fixation. $J$ Hand Surg [Br] 1988;13-B:453-5.

Morgan DAF, Walters JW. A prospective study of 100 consecutive carpal scaphoid fractures. Aust NZ J Surg 1984;54:233-41.

Mulder JD. The results of 100 cases of pseudarthrosis in the scaphoid bone treated by the Matti-Russe operation. J Bone Joint Surg $[\mathrm{Br}]$ 1968;50-B:110-5.

Nakamura R, Horii E, Watanabe K, Tsunoda K, Miura T. Scaphoid non-union: factors affecting the functional outcome of open reduction and wedge grafting with Herbert screw fixation. J Hand Surg $[\mathrm{Br}]$ 1993;18:219-24.

Nakamura R, Imaeda T, Tsuge S, Watanabe K. Scaphoid non-union with DISI deformity: a survey of clinical cases with special reference to ligamentous injury. J Hand Surg 1991;16-B:156-61.

Newport ML, Williams CD, Bradley WD. Mechanical strength of scaphoid fixation. J Hand Surg [Br] 1996;21-B:99-102.

Osterman AL, Mikulics M. Scaphoid nonunion. Hand Clin 1988; 4:437-55

Rankin G, Kuschner SH, Orlando C, et al. A biomechanical evaluation of a cannulated compressive screw for use in fractures of the scaphoid. $J$ Hand Surg [Am] 1991;16:1002-10.

dos Reis FB, Koeberle G, Leite NM, Katchburian MV. Internal fixation of scaphoid injuries using the Herbert screw through a dorsal approach. J Hand Surg [Am] 1993;18:792-7.

Ruby LK, Stinson J, Belsky MR. The natural history of scaphoid nonunion: a review of fifty-five cases. J Bone Joint Surg [Am] 1985; 67-A:428-32.

Russe O. Fracture of the carpal navicular: diagnosis, non-operative treatment, and operative treatment. J Bone Joint Surg [Am] 1960;42-A: 759-68.

Salter RB. Motion versus rest: why immobilise joints? J Bone Joint Surg [Br] 1982;64-B:251-4.

Shaw JA. A biomechanical comparison of scaphoid screws. J Hand Surg 1987;12-A:347-53.

Shaw JA. Biomechanical comparison of cannulated small bone screws: a brief follow-up study. J Hand Surg [Am] 1991;16-A:998-1001.

Shinya K, Herbert TJ. The natural history of 462 cases of scaphoid nonunion: symptoms, degenerative change and the effect of plaster immobilisation. J Hand Surg [Br] 1994;19,Suppl 1:26-7.

Skirven T, Trope J. Complications of immobilisation. Hand Clin 1994; 10:53-61.

Smith K, Helm R, Tonkin MA. The Herbert screw for the treatment of scaphoid fractures. Ann Chir Main Memb Super 1991;10:556-63.

Stark A, Broström L-A, Svartengren G. Scaphoid nonunion treated with the Matti-Russe technique: long term results. Clin Orthop 1987; 214:175-80.

Stark A, Broström L-A, Svartengren G. Surgical treatment of scaphoid non-union: review of the literature and recommendations for treatment. Arch Orthop Trauma Surg 1989;108:203-9.

Steiger R, Sennwald G. Late results of operated scaphoid pseudarthroses. Handchir Mikrochir Plast Chir 1990;22:152-5.

Stewart MJ. Fractures of the carpal navicular (scaphoid): a report of 436 cases. J Bone Joint Surg [Am] 1954;36-A:996-1006.

Tomaino MM, Delsignore J, Burton RI. Long-term results following proximal row carpectomy. J Hand Surg [Am] 1994;19:694-703.

Warren-Smith CD, Barton NJ. Nonunion of the scaphoid: Russe graft vs Herbert screw. J Hand Surg [Br] 1988;13:83-6.

Wildner M. Lost to follow-up. J Bone Joint Surg [Br] 1995;77-B:657.

Zaidemberg C, Siebert JW, Angrigiani C. A new vascularized bone graft for scaphoid nonunion. J Hand Surg [Am] 1991;16:474-8. 